\title{
Mapeamento de áreas de risco para ocorrência da ferrugem do eucalipto no Espírito Santo e extremo sul da Bahia
}

\author{
Willian Bucker Moraes ${ }^{1}$, Waldir Cintra de Jesus Júnior²; Reginaldo Gonçalves Mafia ${ }^{4}$, Wanderson Bucker Moraes²; \\ Roberto Avelino Cecílio ${ }^{3}$
}

1Faculdade de Ciências Agronômicas, Universidade Estadual Paulista "Julio de Mesquita Filho", Departamento de Proteção Vegetal, Botucatu, SP 18610-307, Brasil; ${ }^{2}$ Departamento de Produção Vegetal, Centro de Ciências Agrárias, Universidade Federal do Espírito Santo (UFES), 29500 000, Alegre, ES, Brasil. ${ }^{3}$ Departamento de Ciências Florestais, Centro de Ciências Agrárias, UFES, Alegre, ES, Brasil. ${ }^{4}$ Centro de Pesquisa e Tecnologia - FIBRIA S.A., 29197-900, Aracruz, ES, Brasil.

Autor para correspondência: Willian Bucker Moraes (moraeswb@hotmail.com)

Data de chegada: 04/12/2013. Aceito para publicação em: 20/03/2014.

$10.1590 / 0100-5405 / 1946$

\section{RESUMO}

Moraes, W.B; Jesus Júnior, W.C.; Mafia, R.G.; Moraes, W.B.; Cecílio, R.A. Mapeamento de áreas de risco para ocorrência da ferrugem do eucalipto no Espírito Santo e extremo sul da Bahia. Summa Phytopathologica, v.40, n.2, p.147-155, 2014.

A ferrugem do eucalipto, causada pelo fungo Puccinia psidii Winter, é uma das doenças mais importantes para a eucaliptocultura. O patógeno causa doença principalmente em folhas, hastes e em brotações jovens, sob condições de molhamento foliar noturno acima de 6 horas, por 5 a 7 dias consecutivos, e temperatura na faixa de $18 \mathrm{a} 25^{\circ} \mathrm{C}$, sendo ótimo $23^{\circ} \mathrm{C}$. Considerando a influência das condições climáticas no ciclo de vida do patógeno, o plantio de eucalipto em épocas e em locais desfavoráveis à ocorrência e desenvolvimento do patógeno é uma das possíveis estratégias de manejo integrado da doença. Assim, objetivou-se mapear áreas de risco de ocorrência para a ferrugem do eucalipto no Espírito Santo e extremo sul da Bahia. Para tanto, calculou-se o índice de infecção (II), a partir da média diária da temperatura máxima (T) e da duração do período de molhamento foliar $(\mathrm{H})$, conforme o modelo $\mathrm{II}=-32,263+3,699 \mathrm{~T}+0,461 \mathrm{H}-0,0018 \mathrm{TH}-0,0903 \mathrm{~T}^{2}-0,0068 \mathrm{H}^{2}$.
Os dados utilizados foram obtidos do banco de dados meteorológicos, das regiões de Aracruz e São Mateus (Espírito Santo) e da Região Teixeira de Freitas (Bahia), referentes aos anos de 2001 a 2006, totalizando 26 estações meteorológicas. A partir do índice de infecção, realizou-se o cálculo de um fator de correção, definido como a razão entre o valor 100 e o maior valor interpolado do índice de infecção, para classificar os valores obtidos dentro de uma escala de 0 e 100 pontos de risco, gerando o índice de risco. Com base no valor do índice de risco, elaboraram-se mapas de distribuição espaço-temporal da ocorrência da doença, utilizando o software ArcGis 9.2 ${ }^{\mathrm{TM}}$. Os meses de maio a novembro foram os mais favoráveis para ocorrência da doença. Considerando a distribuição espaço-temporal a metodologia adotada mostrou-se eficiente para o mapeamento do risco de ocorrência da ferrugem do eucalipto para o estado do Espírito Santo e extremo sul da Bahia.

Palavras-chave adicionais: Eucalyptus, Puccinia psidii, áreas de risco, manejo integrado.

\section{ABSTRACT}

Moraes, W.B; Jesus Júnior, W.C.; Mafia, R.G.; Moraes, W.B.; Cecílio, R.A. Mapping of risk areas for the occurrence of eucalyptus rust. Summa Phytopathologica, v.40, n.2, p.147-155, 2014.

Eucalyptus rust caused by Puccinia psidii Winter, is one of the most important diseases of Eucalyptus. The pathogen causes disease mainly in leaves, stems and young shoots, under conditions of leaf wetness up to 6 hours for 5 to 7 consecutive days and temperatures from 18 to $25^{\circ} \mathrm{C}$, with optimum $23^{\circ}$ C. Considering the influence of climatic conditions in the life cycle of the pathogen, the planting of eucalyptus in times and places unfavorable to the occurrence and development of the pathogen is one of the possible strategies for integrated disease management. This study aimed to map risk areas for the occurrence of eucalyptus rust in the Espírito Santo and southern Bahia. Therefore, was calculated the rate of infection (II) from the average daily maximum temperature $(\mathrm{T})$ and duration of leaf wetness $(\mathrm{H})$ as the model II $=-32.263+3.699 \mathrm{~T}+0.461 \mathrm{H}-\mathrm{TH} 0.0018-0.0903 \mathrm{~T} 2-0.0068 \mathrm{H} 2$. The data used were obtained from the meteorological database, of the Região Aracruz and São Mateus (Espírito Santo) and Região Teixeira de Freitas (Bahia) for the years 2001 to 2006, a total of 26 weather stations. From the rate of infection was carried out to calculate a correction factor, defined as the ratio between the value 100 and the highest interpolated value of infection rate, to classify the values within a range from 0 to 100 points risk, generating the risk index. Based on the value of risk index, drawn up maps of spatial and temporal distribution of disease occurrence, using the software ArcGIS $9.2 \mathrm{TM}$. According to the results it is concluded that the months from May to November are the most favorable for the occurrence of the disease. The adopted methodology was efficient for the mapping of the risk of eucalyptus rust, considering the spatial and temporal distribution.

Additional keywords: Eucalyptus, Puccinia psidii, risk areas, integrated management. 
No Brasil, as áreas ocupadas com plantios de eucalipto são de aproximadamente 5,1 milhões de hectares, sendo os principais Estados produtores Minas Gerais, São Paulo, Bahia, Mato Grosso do Sul e Rio Grande do Sul (1). Em função das condições edafo-climáticas e do nível tecnológico adotado, o setor florestal brasileiro é um dos mais competitivos do mundo.

As principais doenças do eucalipto são eficientemente controladas pela seleção e pelo plantio de clones resistentes, o que somado ao mapeamento de áreas de risco para ocorrência de doenças de planta, garantem a proteção florestal quanto ao controle de doenças (14). A ferrugem do eucalipto, causada pelo fungo Puccinia psidii Winter, é uma importante doença da cultura, em função dos danos causados e da sua influência sobre o manejo da cultura, podendo afetar, inclusive, a condução de brotação em épocas favoráveis para ocorrência da doença, considerando clones suscetíveis. A predominância de temperaturas do ar, variando entre 18 e $25^{\circ} \mathrm{C}$, associada a períodos com molhamento foliar superiores a 6 horas por 5 a 7 dias consecutivos, bem como a existência de órgãos juvenis, incluindo folhas novas e terminais de crescimento, favorecem as infecções pelo patógeno (16). O fungo infecta folhas do estádio juvenil de plantas novas ou brotações após o corte das árvores. Além do eucalipto, o patógeno também causa doença em várias outras espécies, pertencentes às famílias Myrtaceae e Heteropixidaceae $(3,4,8,9)$.

$\mathrm{O}$ desenvolvimento de doenças em plantas está ligado a fatores relacionados ao patógeno, ao hospedeiro e ao ambiente. Cada um desses fatores exerce papel fundamental no desenvolvimento de epidemias e deve ser estudado em particular para o entendimento dos mecanismos que afetam o ciclo da doença. Entretanto, o ambiente exerce papel preponderante sobre os demais, uma vez que também os influencia. As condições climáticas afetam o desenvolvimento e a suscetibilidade da planta hospedeira, a multiplicação e sobrevivência do patógeno, assim como a interação entre ambos $(11,20)$. Portanto, o zoneamento de áreas de risco ao estabelecimento de doenças permite explorar o princípio de escape (local e época de plantio) (2), sendo possível definir o risco de ocorrência de uma determinada doença em uma região (20).

A partir de séries históricas de dados climáticos, obtidos de redes de estações meteorológicas, podem-se elaborar mapas de zonas de risco de epidemias. No caso de doenças de plantas, os mapas de zonas de risco, acoplados aos modelos de simulação, são úteis para indicar áreas geográficas ou até mesmo, épocas do ano mais favoráveis à ocorrência de epidemias (13). O uso do Sistema de Informações Geográficas (SIG) permite realizar análises complexas ao integrar informações de diversas fontes e criar bancos de dados georreferenciados. $\mathrm{O}$ geoprocessamento, atividade central do SIG, permite estudar mudanças em processos e suas interações, nas dimensões espaço-temporal, e criar documentos cartográficos de alta qualidade, com incertezas estimadas e possibilidade de estabelecer níveis de confiança (10).

O zoneamento de áreas de risco para ocorrência da ferrugem do eucalipto é um importante passo para o estabelecimento de um plano de manejo integrado para esta doença. Sendo assim, o presente trabalho objetivou mapear áreas de risco de ocorrência da ferrugem do eucalipto, considerando as condições climáticas ideais para o patógeno e o emprego de ferramentas do SIG.

\section{MATERIAL E MÉTODOS}

\section{Caracterização das áreas de estudo}

Foram escolhidas três regiões para o mapeamento de risco da ocorrência da ferrugem do eucalipto, com base em avaliações qualitativas sobre ocorrência da doença (5): Aracruz e São Mateus no Estado do Espírito Santo e Teixeira de Freitas no Estado da Bahia.

Utilizaram-se dados climáticos horários, provenientes de 26 estações meteorológicas automatizadas (Figura 1), sob responsabilidade da Aracruz Celulose S.A., distribuídas nas Regiões de Aracruz-ES ( 9 estações, abrangendo 176.688,36 ha), São Mateus-ES (8 estações, abrangendo 700.482,78 ha) e Teixeira de Freitas-BA (9 estações, abrangendo 1.033.226,91 ha), referentes ao período compreendido entre os anos de 2001 e 2006.

\section{Dados climáticos}

Os dados foram coletados em valores horários, os quais foram convertidos em médias diárias e posteriormente em médias mensais. As variáveis climáticas obtidas foram temperatura máxima, temperatura média, temperatura mínima, precipitação e umidade relativa do ar, durante o período de 2001 a 2006. Para o cálculo da duração do período de molhamento foliar total (DPMFT) e duração do período de molhamento foliar contínuo (DPMFC), considerou a média do números de horas por dia para cada mês com umidade relativa do ar igual ou superior a $90 \%(16)$.

\section{Cálculo do índice de infecção}

O cálculo do índice de infecção (II) foi realizado a partir dos dados meteorológicos horários que foram convertidos em médias diárias e posteriormente em médias mensais de temperatura máxima $(\mathrm{T})$ e de duração do período de molhamento foliar total $(\mathrm{H})$, onde $\mathrm{H}$ é a soma das horas do dia com umidade relativa superior a $90 \%$.

Para realizar o cálculo do índice de infecção foi utilizado o modelo proposto por (16), sendo II $=-32,263+3,699 \mathrm{~T}+0,461 \mathrm{H}-0,0018 \mathrm{TH}$ $-0,0903 \mathrm{~T}^{2}-0,0068 \mathrm{H}^{2}\left(\mathrm{R}^{2}=0,77\right)$, onde $\mathrm{T}$ é a média da temperatura máxima $\left({ }^{\circ} \mathrm{C}\right)$ e $\mathrm{H}$ é a duração média diária mensal do molhamento foliar (horas).

\section{Elaboração dos mapas de risco}

A partir dos cálculos do índice de infecção, com base na equação descrita por (16), elaboraram-se os mapas de distribuição espaçotemporal do risco de ocorrência da ferrugem do eucalipto para as três regiões avaliadas.

Os índices de infecção foram gerados para as respectivas estações meteorológicas. Posteriormente, com o auxílio do software ArcGis 9.2 $2^{\mathrm{TM}}$ estabeleceu-se uma relação entre o posicionamento geográfico das estações e os respectivos índices calculados, permitindo a disponibilização dos índices em uma base de dados geográficos. Após esta etapa, realizou-se a interpolação dos dados, com a geração de "layers" com auxílio da extensão Spatial Analyst do ArcGis 9.2 2 .

A interpolação "Spline" foi empregada para suavizar as estimativas dos índices de infecção e o método "Tension", com peso 5, para manter os valores interpolados mais próximos dos valores de índice de infecção calculados para as diferentes estações meteorológicas, evitando distorções nas estimativas. O número de pontos empregados para executar as interpolações em cada célula do "raster" correspondeu ao número total de estações meteorológicas. A resolução empregada foi de $30 \times 30 \mathrm{~m}$.

Após a espacialização dos índices de infecção, os «layers» obtidos foram corrigidos somando-se aos dados interpolados o módulo do menor valor obtido, de forma a corrigir os índices de infecção para valores positivos, pois a equação do II gerou valores de menos infinito a mais infinito, dependo das condições climáticas favoráveis a ocorrência 


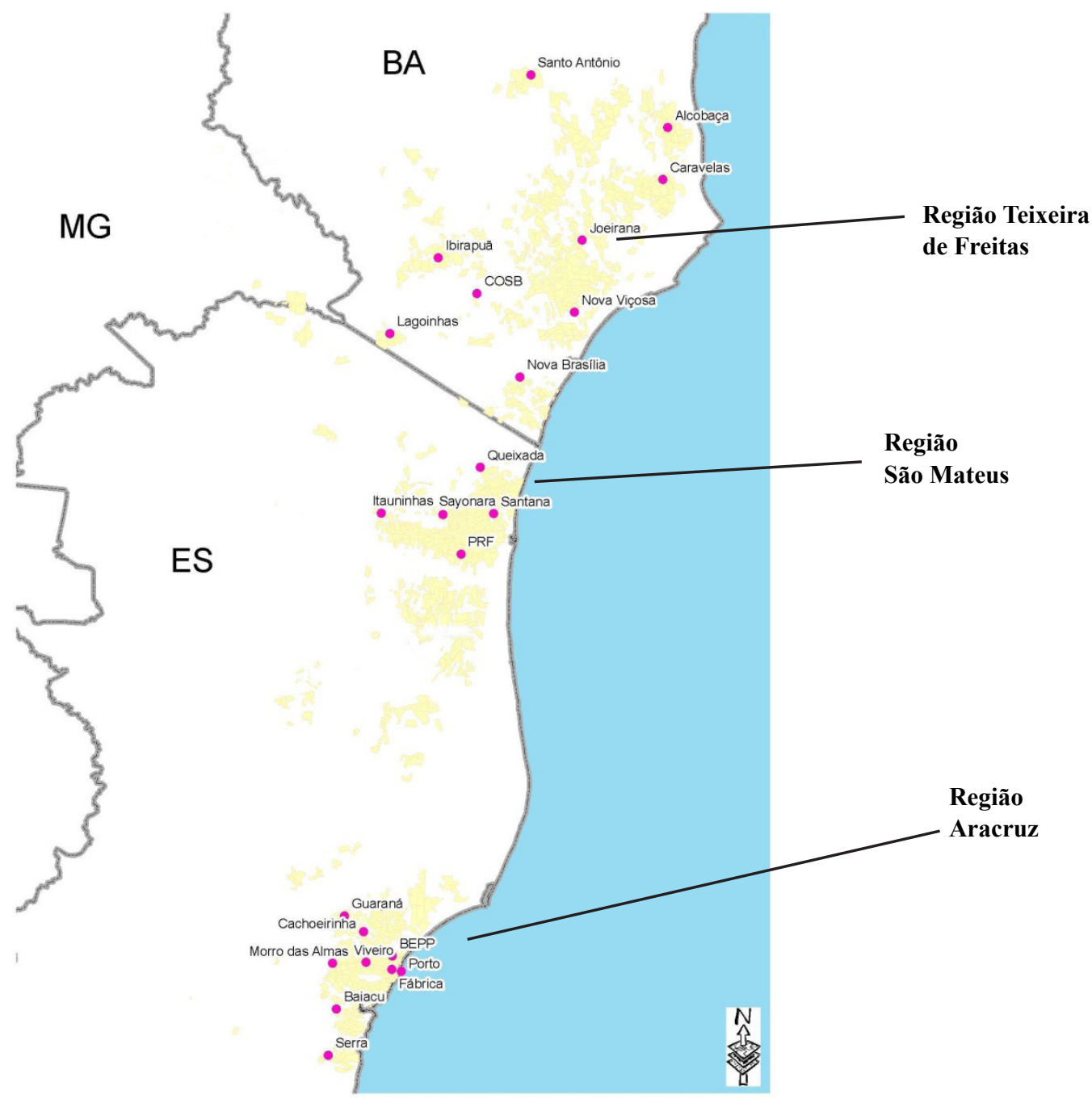

Figura 1. Distribuição das estações meteorológicas nas três regiões de estudo. Cada ponto representa a posição de uma estação meteorológica.

Fonte: Aracruz Celulose S.A.

da doença. Posteriormente, para classificar os valores obtidos dentro de uma escala de 0 a 100 pontos de risco, realizou-se o cálculo de um fator de correção (FC), definido como a razão entre o valor 100 e o maior valor interpolado do índice de infecção, utilizando a seguinte equação:

$$
\begin{aligned}
& \mathrm{R}=\mathrm{M}-\mathrm{m} \\
& \mathrm{FC}=100 / \mathrm{R} \\
& \mathrm{IR}=\mathrm{FC} *(\mathrm{II}-\mathrm{m})
\end{aligned}
$$

Em que: $\mathrm{R}=$ Range; $\mathrm{M}=$ maior índice $; \mathrm{m}=$ menor índice; $\mathrm{FC}=$ Fator de correção; IR = Índice de risco e II = índice de infecção

Após esta etapa, multiplicou-se o fator de correção pelos «layers» das três localidades estudadas, com auxílio da extensão Spatial Analyst do ArcGis 9.2 ${ }^{\mathrm{TM}}$, obtendo os mapas finais das áreas de risco.

\section{RESULTADOS}

Embora as regiões Aracruz e São Mateus no Espírito Santo e Teixeira de Freitas na Bahia apresentem semelhanças em relação ao clima, todavia algumas diferenças foram observadas (Figura 2). As temperaturas médias da máxima, média e mínima e da duração do período de molhamento foliar total de todas as estações meteorológicas de cada área em estudo, podem ser observadas nas Figuras 2a, 2c e 2e, assim como as médias de umidade relativa e precipitação (Figuras 2b, $2 \mathrm{~d}$ e $2 \mathrm{e}$ ). As três Regiões em estudo apresentaram duração do período de molhamento foliar total superior a 6 horas, a exceção dos meses de agosto, setembro e outubro, para região de Aracruz (Figuras 2a, 2c e 2e).

A região de Aracruz apresentou um maior número de meses com média de valores de temperatura máxima, média e mínima entre 21 a $23{ }^{\circ} \mathrm{C}$ (Figuras 2a), os quais são considerados ótimos para o desenvolvimento da doença (16), ao passo que para as regiões São Mateus e Teixeira de Freitas apresentaram um menor número de meses (Figura $2 \mathrm{c}$ e 2e). No que diz respeito à distribuição temporal da ferrugem do eucalipto, verificou-se que os meses de maio a novembro apresentaram melhores condições climáticas para ocorrência da doença, com temperaturas em torno de 18 a $25^{\circ} \mathrm{C}$, enquanto que os meses de dezembro a abril observou-se médias de temperatura superiores a 25 ${ }^{\circ} \mathrm{C}$, as quais são consideradas desfavoráveis à ocorrência da doença.

Em relação ao período de molhamento foliar contínuo, observou-se horas de molhamento foliar superiores a 6 horas, com temperaturas entre 
a)

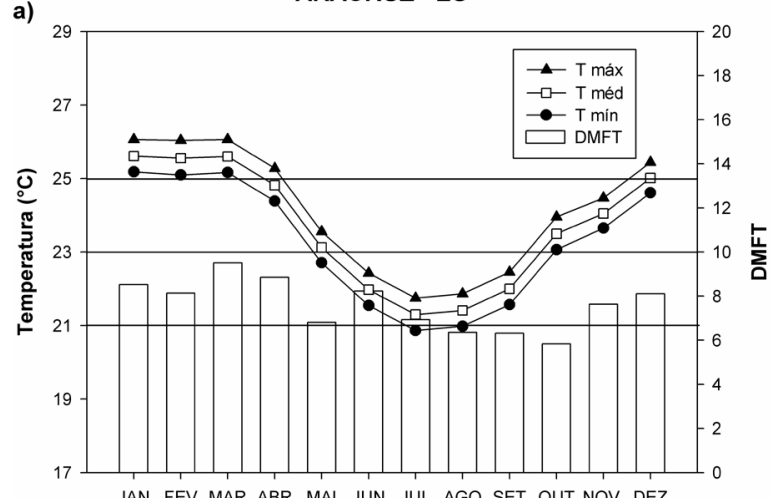

JAN FEV MAR ABR MAI JUN JUL AGO SET OUT NOV DEZ

Mês

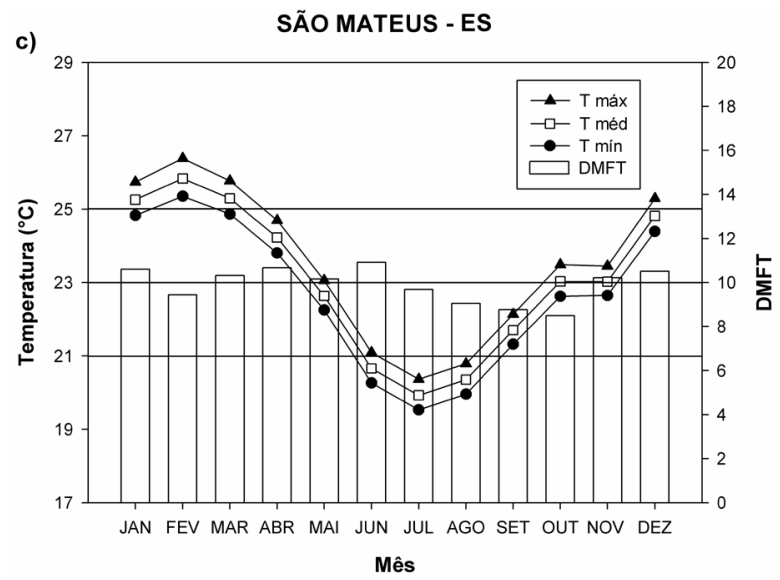

Mês

e)

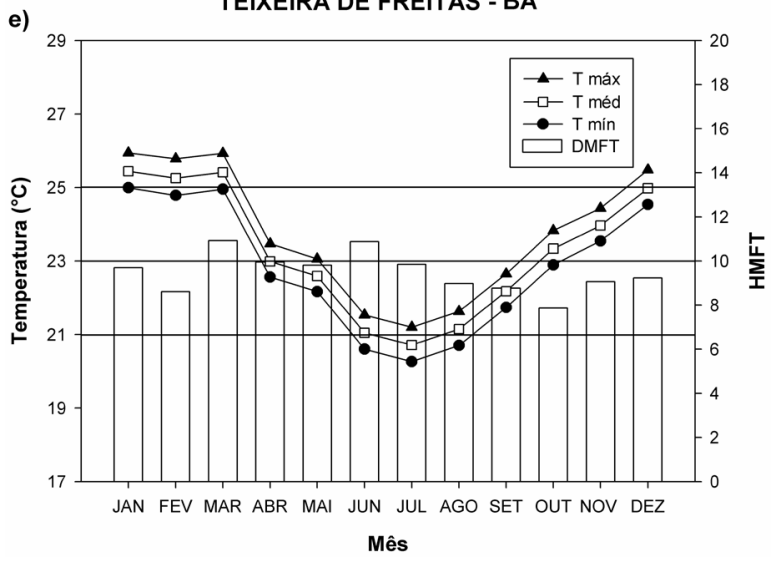

b)

ARACRUZ - ES

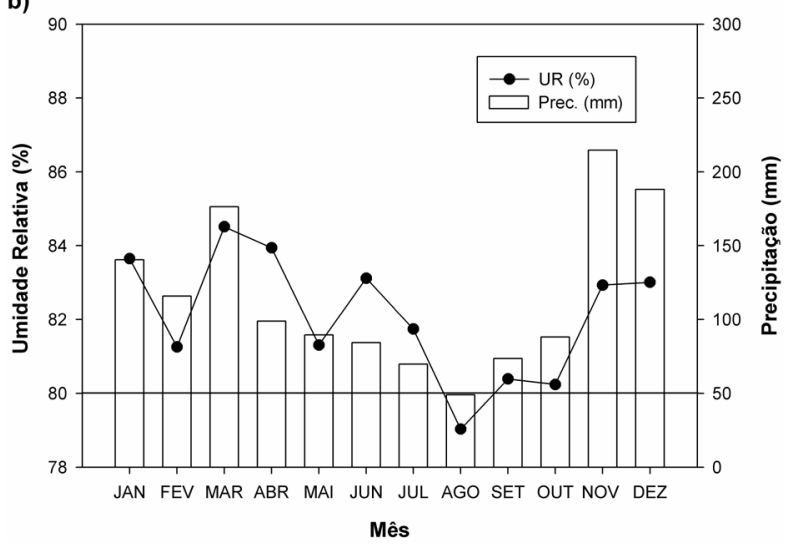

d) SÃO MATEUS - ES

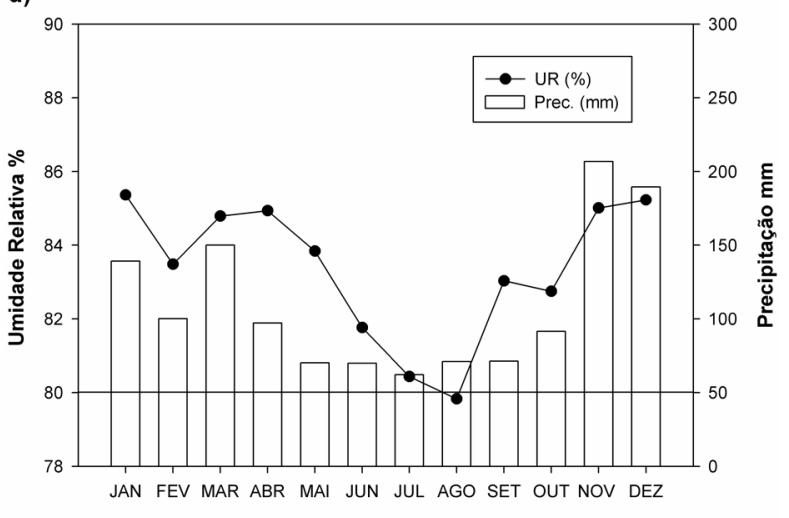

Mês

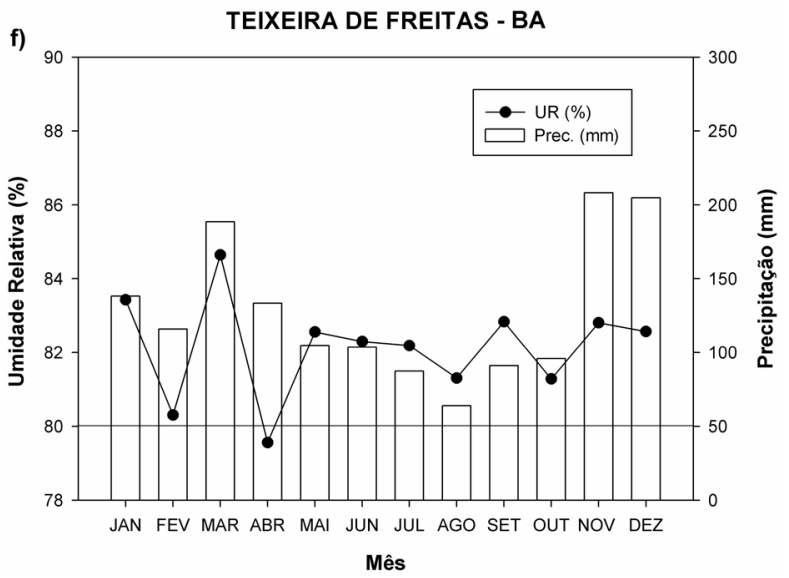

Figura 2 . Temperaturas médias máxima (T máx), média (T méd) e mínima (T min) e da duração do período de molhamento foliar total (DMFT), umidade relativa (UR) e precipitação (Prec.), para as regiões em estudo.

19 a $25^{\circ} \mathrm{C}$, para as três regiões em estudo, com exceção de outubro em Aracruz (Figura 3a, 3b e 3c).

Com base nos resultados da distribuição espaço-temporal da doença para as três regiões estudadas (Figuras 4, 5, 6 e Tabela 1), verificou-se que os meses de maio a novembro apresentaram maior favorabilidade para ocorrência da doença, com porcentagem média geral de 70,24, enquanto que para os meses de dezembro a abril a porcentagem média geral foi de 51,79. O mês de abril apresentou uma faixa de transição da época desfavorável para a época favorável, dado que houve redução nos valores de temperatura, ao passo que, o mês de novembro apresentou uma faixa de transição da época favorável para a época desfavorável a ocorrência da ferrugem do eucalipto, uma vez que houve um aumento da temperatura (Figuras 2a, 2c, 2e).

De forma geral, observou-se maior favorabilidade de ocorrência da doença na região de Aracruz. Para esta região, o índice de risco médio da doença foi de $68,8 \%$ (Tabela 1 ), fato que pode ser explicado pelos altos valores de duração do período de molhamento foliar (superior a 6 horas) e temperaturas máximas próximas a $23{ }^{\circ} \mathrm{C}$, nos meses de maio a novembro, os quais são os mais favoráveis a ocorrência da doença (Figuras 2a e 3a). Vale ressaltar que apesar da maior favorabilidade nessa região, algumas áreas podem ser consideradas de escape à doença, com temperaturas superiores a $25^{\circ} \mathrm{C}$. Para a região de São Mateus 

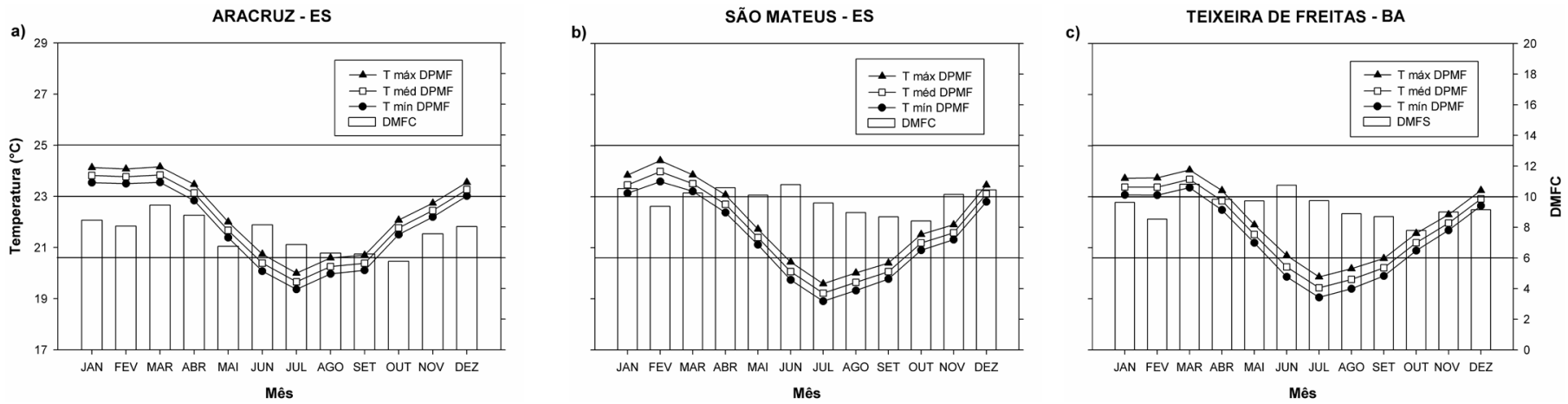

Figura 3. Temperaturas médias máxima (T máx), média (T méd) e mínima (T min) e do número de horas de molhamento foliar contínuo (DMFC) de todas as estações meteorológicas de cada Região em estudo, durante o período de molhamento foliar contínuo.
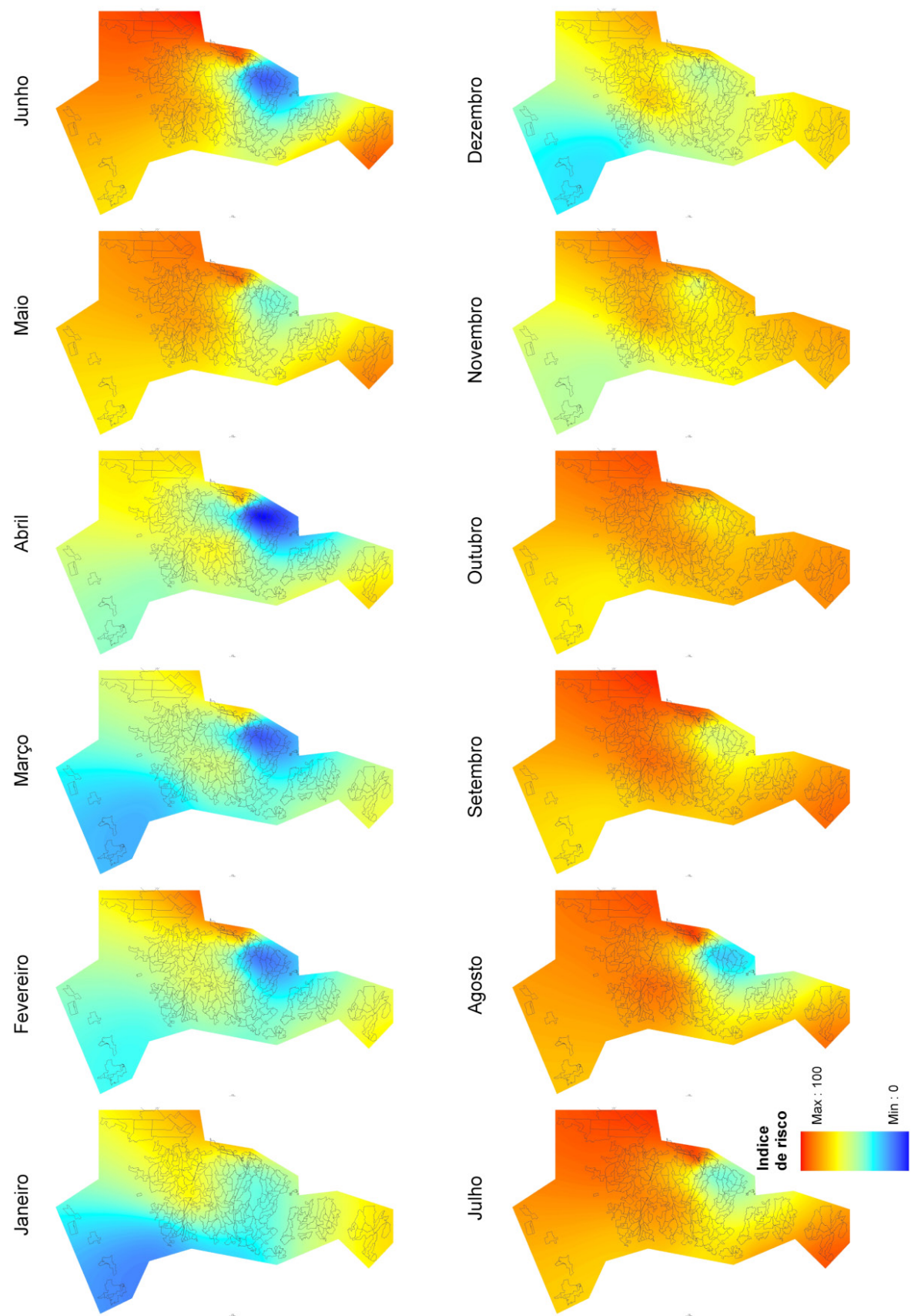

Figura 4. Distribuição espaço-temporal das áreas de risco de ocorrência da ferrugem do eucalipto para região de Aracruz-ES. 
verificou-se menor índice de risco à ferrugem com porcentagem dos valores dos índices de risco médio de 58,9\% (Tabela 1), havendo neste local maior homogeneidade quanto à favorabilidade de ocorrência da doença ao longo do ano (Figura 5). A menor favorabilidade nessa Região provavelmente pode ser explicada pela ocorrência de poucos meses com temperaturas próximo de $23{ }^{\circ} \mathrm{C}$ (Figura 2c). Em Teixeira de Freitas, a porcentagem dos valores dos índices de risco médio de foi de $60,33 \%$, apesar de apresentar um valor médio de risco, foram detectadas tanto áreas com índices de risco da doença próximos a 0 (áreas consideradas escape) quanto a $100 \%$.

Tal diferença provavelmente ocorreu em função da localização das áreas dentro da Região, uma vez que se têm áreas próximas ao litoral e outras mais no interior (Figura 6). Para Aracruz e Teixeira de Freitas, o maior valor médio de risco calculado foi de $83 \%$ e $74 \%$, respectivamente, para o mês de setembro, enquanto para São Mateus, o maior valor observado foi $73 \%$ para o mês de outubro (Tabela 1).

\section{DISCUSSÃO}

O presente trabalho é pioneiro na utilização do SIG para interpolação e mapeamento de áreas favoráveis à ocorrência da ferrugem do eucalipto, com base no modelo proposto por (16). A técnica de geoprocessamento possibilita análises complexas ao integrar informações de diversas fontes, permitindo estudar a dinâmica espaçotemporal de epidemias de doenças de plantas, o que facilitará as tomadas de decisões, permitindo o plantio e o manejo da cultura, explorando áreas e épocas escapes para ferrugem do eucalipto.

Os maiores índices de risco para a distribuição temporal da ferrugem do eucalipto foram encontrados para os meses de maio a novembro, com exceção de junho (Teixeira de Freitas - BA), principalmente pelo fato da temperatura permanecer na faixa entre 19 a $25^{\circ} \mathrm{C}$, com duração do período de molhamento foliar sempre superior a 6 horas, sendo essas as condições favoráveis à ocorrência da doença (16). (7) em observações realizadas a campo para Teixeira de Freitas/BA durante o período de 1987 a 1989, concluiu que para os anos em estudos, os meses de março a novembro apresentaram maior incidência da doença. Da mesma forma (17) para a região de Luiz Antônio/SP durante o período 2001 a 2004, concluiu que os meses com maior incidência da doença foram de maio a dezembro, principalmente pelas condições de alta umidade relativa e temperatura na faixa de 15 a $25^{\circ} \mathrm{C}$.

Para as áreas em estudo a duração do período de molhamento foliar não foi limitante para ocorrência da doença. A região de Aracruz apresentou o maior número de meses favoráveis com temperaturas entre 21 a $23^{\circ} \mathrm{C}$, considerada ótimo pelo modelo proposto por (16) para o presente patossistema. Isto explica a diferença nos valores do índice de risco entre as regiões em estudo, uma vez que, as regiões de São Mateus e Teixeira de Freitas apresentaram um menor número de meses favoráveis com temperaturas próximas a $23^{\circ} \mathrm{C}$. Desta forma para este estudo, o modelo apresentou-se muito útil para a avaliação temporal, porém com algumas limitações para a avaliação espacial em condições de campo.

Considerando as diferenças dos valores do índice de risco dentro de cada região em estudo, observa-se que a localização de cada estação meteorológica representa as diferenças climáticas em cada ponto de coleta dos dados, o que pode ser utilizado para explicar as áreas de escape e de maior favorabilidade em um mesmo mês. A densidade de estações meteorológicas e a distância entre elas para cada área, provavelmente influenciou nas interpolações, pois valores da mesma classe podem ter sido atribuídos a grandes extensões, fato que pode ser observado para a região de São Mateus, sendo resultado semelhante encontrado por (18) para o mal das folhas da seringueira.

As três regiões em estudo possuem grandes áreas com plantios de eucalipto. Com base nos mapas de risco observam-se para essas Regiões áreas livres ou com baixo índice de risco de ocorrência da doença. As áreas de escape à ferrugem do eucalipto para a região de Aracruz situam-se na região sudeste, ao passo que para São Mateus são encontradas na região central tendendo para o norte e para Teixeira de Freitas observa áreas bem definidas na região sudoeste. Para estas áreas é recomendado o plantio de clones moderadamente suscetíveis, assim como para as áreas de maior favorabilidade o plantio de clones resistentes ou tolerantes. De forma geral, o plantio e a condução de

Tabela 1 - Índice de risco médio mensal de ocorrência da ferrugem do eucalipto em função da época do ano e do local estudado.

\begin{tabular}{cccc}
\hline & & Índice de Risco (\%)* & \\
\cline { 2 - 4 } Meses & Aracruz & São Mateus & Teixeira de Freitas \\
\hline JAN & 55,34 & 38,22 & 49,26 \\
FEV & 56,87 & 51,82 & 56,77 \\
MAR & 48,45 & 47,04 & 40,85 \\
ABR & 57,18 & 51,28 & 56,84 \\
MAI & 77,47 & 62,73 & 62,15 \\
JUN & 73,17 & 58,59 & 54,82 \\
JUL & 81,72 & 67,66 & 66,50 \\
AGO & 80,68 & 71,45 & 71,55 \\
SET & 83,03 & 74,22 & 72,79 \\
OUT & 79,45 & 71,37 & 73,00 \\
NOV & 70,19 & 59,09 & 63,40 \\
DEZ & 61,81 & 49,11 & 55,96 \\
\hline MÉDIA & $\mathbf{6 8 , 7 8}$ & $\mathbf{5 8 , 8 7}$ & $\mathbf{6 0 , 3 3}$ \\
\hline
\end{tabular}

*Índice de risco $\leq 55=$ baixo, 56 a $70=$ médio e $\geq 70=$ alto. 

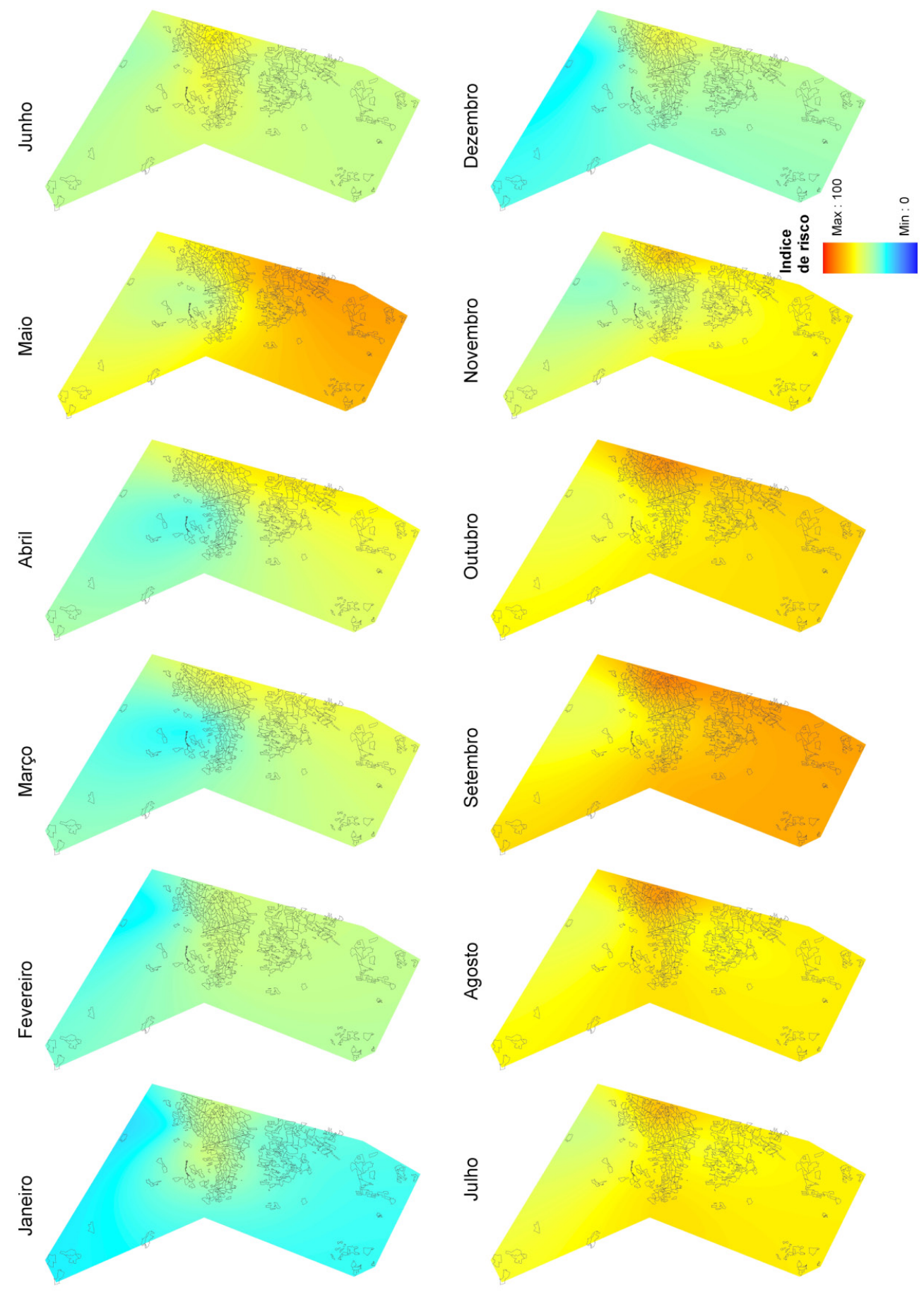

Figura 5 - Distribuição espaço-temporal das áreas de risco de ocorrência da ferrugem do eucalipto para região de São Mateus-ES.

rebrotas devem ser realizados nessas regiões de agosto a outubro, de modo a evitar condições do hospedeiro (folhas, hastes e brotações jovens) que são favoráveis a infecção do patógeno $(3,4,8,9)$ nas épocas mais favoráveis a ocorrência da doença.

Estudos sobre o mapeamento climático mencionam a importância de identificar áreas de alto risco de ocorrência para várias doenças, principalmente no que se diz respeito à introdução de doenças quarentenárias e ao plantio de hospedeiros suscetíveis e moderadamente suscetíveis $(5,6,15,19)$. Grande parte destes estudos utiliza a base de dados do programa CLIMEX e avaliações qualitativas, que é uma alternativa viável para patossistemas que não possuam um modelo específico desenvolvido, porém o uso de modelo específico para patossistemas tem se mostrado mais recomendado (18).

\section{CONCLUSÕES}

O índice de risco de ocorrência de ferrugem variou em função da área estudada e dos meses do ano. De forma geral, os meses de maio 

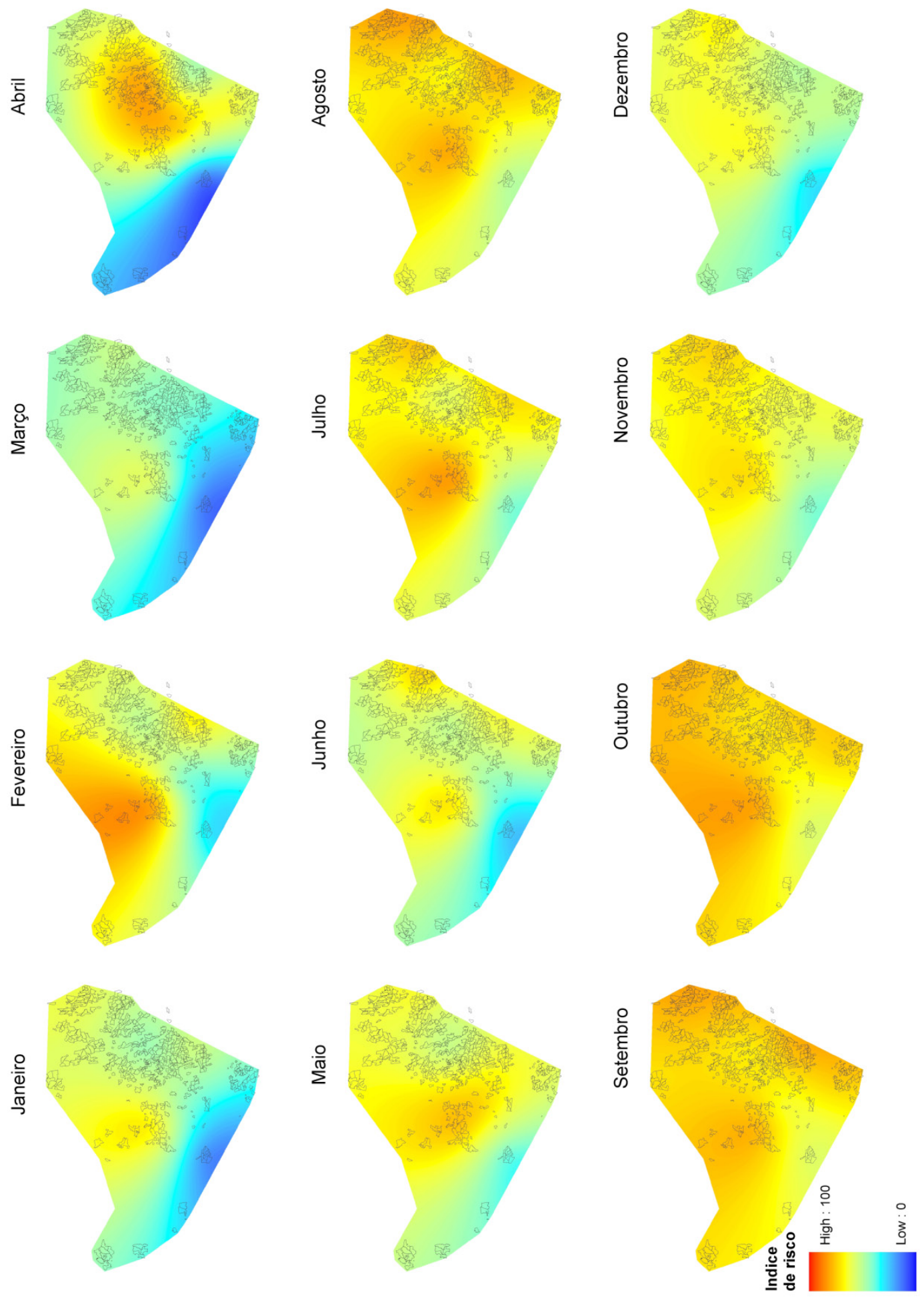

Figura 6 - Distribuição espaço-temporal das áreas de risco de ocorrência da ferrugem do eucalipto para a região de Teixeira de Freitas-BA.

a novembro apresentaram maior favorabilidade para ocorrência da doença nas áreas estudadas;

A região de Aracruz apresentou maiores valores médios de índices de risco de ocorrência da doença, ao passo que São Mateus e Teixeira de Freitas tiveram índices semelhantes;

A metodologia adotada para o mapeamento do risco de ocorrência da ferrugem do eucalipto, foi eficiente para avaliação espaço-temporal, as áreas e meses ideais para a programação de época de colheita, condução de rebrota e plantio de clones de eucalipto considerando o nível de resistência para esta doença;

A distribuição espaço-temporal pode ser utilizada em estudos futuros para outras regiões, como uma ferramenta valiosa para tomadas de decisão, o que contribuirá para um melhor planejamento e manejo da cultura do eucalipto. 


\section{REFERÊNCIAS BIBLIOGRÁFICAS}

1. Abraf: Associação Brasileira de Produtores de Florestas Plantadas, 2013. Anuário Estatístico da ABRAF: ano base 2012, Brasília.

2. Agrios, G. N. Plant Pathology. 6 ed. San Diego: Academic Press, 2005. p. 489-498.

3. Alfenas, A.C.; Zauza, E.A.V. ; Wingfield, M.J; Roux, Glenc, J.M. Heteropyxis natalensis, a new host of Puccinia psidii rust. Australasian Plant Pathology, Auckland, v.34,p. 285-286, 2005.

4. Alfenas, A.C.; Mafia, R.G. Controle integrado de doenças em viveiros clonais e aspectos relativos à ferrugem (Puccinia psidii) do eucalipto. Fitopatologia Brasileira, Brasília, v. 28, p. 156-163, 2003.

5. Booth, T.H.; Old, K.M.; Jovanovic, T. A preliminary assessment of high risk areas for Puccinia psidii (Eucalyptus rust) in the Neotropics and Australia. Agriculture, Ecosystems and Environment, Amsterdam, v. 82, p. 295-301, 2000a

6. Booth, T.H.; Jovanovic, T.; Old, K.M.; Dudzunski, M.J. Climatic mapping to identify high-risk areas for Cylindrocladium quinqueseptatum leaf blight on eucalyptus in mainland South East Asia and around the world. Environmental Pollution, Barking, v. 108, p. 365-372, 2000b.

7. Carvalho, A.O.; Alfenas, A.C.; Maffia, L.A.; Carmo, M.G.F. Avaliação do progresso da ferrugem (Puccinia psidii) em brotações de Eucalyptus cloeziana no sudeste da Bahia de 1987 a 1989. Revista Árvore, Viçosa, v. 18, p. 265-274, 1994.

8. Coutinho, T.A.; Wingfield, M.J.; Alfenas, A.C., Crous, P.W. Eucalyptus rust: a disease with the potential for serious international implications. Plant Disease, Saint Paul, v. 82, p. 819-925, 1998.

9. Glen, M.; Alfenas, A.C.; Zauza, E.A.V.; Wingfield, M.J.; Mohammed, C. Puccinia psidii: a threat to the Australian environment and economy - a review. Australasian Plant Pathology, Auckland, v. 36, p. 1-6, 2007.

10. Harmon, J.E.; Anderson, S.J. The design and implementation of geographic information systems. New Jersey: John Wile \& Sons, 2003. $264 \mathrm{p}$.

11. Jesus Junior, W.C.; Vale, F.X.R.; Moraes, W.B.; Zambolim, L.; Ramos, F.A. Critérios epidemiológicos para tomada de decisão no manejo de doenças de plantas. In: Jesus Junior, W.C.; Polanczyk, R.; Pratissoli, D.; Pezzopane, J.E.M.; Santiago, T. (Ed.). Atualidades em Defesa Fitossanitária. Visconde do Rio Branco: Suprema Gráfica e Editora, 2007. p.307-326.

12. Joffily, J. Ferrugem do eucalipto. Bragantia, Campinas, v. 4, p. 475-487, 1944

13. Lopes, M.V.; Barreto, M.; Scaloppi, E.A.G.; Barbosa, J.C.; Brunini, O. Mapas de zonas de risco de epidemias e zoneamento agroclimático para o Cancro Cítrico no Estado de São Paulo. Summa phytopathologica, Botucatu, v. 34, p. 349-353, 2008.

14. Mafia, R.G. Manejo integrado de doenças: um bom exemplo florestal. In.: ENCONTRO BRASILEIRO DE SILVICULTURA. 1, 2008, Curitiba Anais... Curitiba: SBS, 2008. p. 163-182.

15. Paul, I.; Jaarsveld, A.S.V.; Korstenc, L.; Hattingh, V. The potential global geographical distribution of Citrus Black Spot caused by Guignardia citricarpa (Kiely): likelihood of disease establishment in the European Union. Crop Protection, Guildford, v. 24, p. 297-308, 2005.

16. Ruiz, R.A.R.; Alfenas, A.C.; Ferreira, F.A.; Vale, F.X.R. Do. Influência da temperatura, do tempo de molhamento foliar, fotoperíodo e da intensidade de luz sobre a infecção de Puccinia psidii em eucalipto. Fitopatologia Brasileira, Brasília, v. 14, p. 55-61, 1989.

17. Santos, C.A.G. Estudos epidemiológicos da ferrugem do eucalipto causado por Puccinia psidii em plantios irrigados. 2006. 75f. Dissertação (Mestrado em Proteção de Plantas), Programa de Pós-Graduação em Proteção de Plantas, Faculdade de Ciências Agronômicas da UNESP, Botucatu, 2006.

18. Silva, L.G.C. Zoneamento do risco de ocorrência do mal das folhas da seringueira com base em sistemas de informações geográficas. 2007. 46f Dissertação (Mestrado em Fitopatologia), Programa de Pós-Graduação em Fitopatologia, Universidade Federal de Viçosa, Viçosa, 2008.

19. Staden, V.V.; Erasmus, B.F.N.; Roux, J.; Wingfield, M.J.; Jaarsvel, A.S.V. Modelling the spatial distribution of two important South African plantation forestry pathogens. Forest Ecology and Management, Amsterdam, v. 187, p. 61-73, 2004.

20. Vale, F.X.R.; Jesus Junior, W.C.; Zambolim, L. Epidemiologia Aplicada ao Manejo de Doenças de Plantas. Belo Horizonte: Perfill Editora, 2004, 532p. 